\title{
Research on the Development and Construction of Information Technology Superiority Subject Management in Agricultural Colleges of Jilin Province

\author{
Liying $\mathrm{CaO}^{1, \mathrm{a}}$, Yidan Shao ${ }^{2, \mathrm{a}}$,Tengda Qie ${ }^{1, \mathrm{a}}$ and Guifen Chen ${ }^{1, \mathrm{a}}$ \\ 1 Jilin Agricultural University, Changchun 130118,China \\ ${ }^{2}$ China University of Mining and Technology, Beijing 100083, China \\ a Caoliying99@163.com
}

\begin{abstract}
Keywords: Information Technology, Superiority Subject Management, Agricultural Colleges, Jilin Province
\end{abstract}

\begin{abstract}
This thesis focuses on microscopic study, with advantages of agricultural colleges and universities information technology subject construction in Jilin Province as an entry point, using the comparative research method, statistical evaluation method, using the web of science subject evaluation tool and biometrics method, combined with various types of citation database, comparison and analysis and evaluation on the strength of Jilin Province various colleges and universities information technology professionals in the fields of the same advantages, the clear advantage of the subject in the field of development trend, find the Jilin Province Agricultural Colleges and universities information technology potential advantages, put forward the corresponding countermeasures, in order to improve the competitiveness of the agricultural colleges and universities advantages of disciplines.
\end{abstract}

\section{Introduction}

In China, the construction of key disciplines in Universities in Beijing is mainly in the form of subject group, which is a basic concept of construction. In 2005, Beijing Municipal Commission of education in conjunction with the Beijing Municipal Development and Reform Commission, Beijing Municipal Finance Bureau, the Beijing Municipal Industrial Promotion Bureau, Beijing Science and Technology Commission and other departments, aiming at the problem that the single subject service field is relatively narrow, not with the economic and social development in Beijing to achieve effective docking, took the lead in the domestic establishment of Humanities and Social Sciences, natural sciences two categories, 11 university science group. Heilongjiang Province in order to build a group of high level of discipline, service leading industry group development, according to the requirements of the higher education of Heilongjiang Province construction planning formulated the Heilongjiang province key discipline in Colleges and universities group project construction planning ".

In Japan, some university in order to further promote the integration between disciplines, promote the development of creative subject and special construction comprehensive research building, the interdisciplinary and trend of integration of different graduate students put together to carry out scientific research and academic activities, multidisciplinary exchange and the fusion provides a platform. In the United States, Massachusetts Institute of technology through interdisciplinary courses and cross discipline research centers to achieve a discipline comprehensive crossover and to training with interdisciplinary knowledge talent and create interdisciplinary high level results. The structure of the subject is basically a net structure. In Switzerland, Zurich University through the development of interdisciplinary, multidisciplinary and interdisciplinary of mode of teaching and scientific research projects, pushed between the disciplines of traditional barriers, breaking isolation of interdisciplinary, establish the interdependence of different disciplines. 


\section{The significance of the research on the subject group of information technology superiority}

As an academic organization, the subject is the most basic unit of the University. The construction of the subject is the key to the development of the University. The development level of the university is largely determined by the level of the discipline construction. Characteristic is the advantage, advantages cast strength, strength to promote the development of. The characteristics of the university is a university formed in the long development of more stable proprietary or significant development and recognized, unique, excellent school characteristics. The discipline group refers to around a common academic research field, a number of similar disciplines or related disciplines cross fusion and interaction, forming an organic subject group. Discipline advantage group can drive the development of adjacent disciplines, to form a group of discipline advantage, improve the quality of personnel training, to enhance the school's competitiveness, and can produce good economic and social benefits in the social and economic development, fully reflect the development characteristic and the science and technology level of a country, a region economy development.

The problem with group construction of characteristic agricultural information technology disciplines is always an important research topic in agricultural colleges. With the agricultural characteristics of information technology is to train senior specialized agricultural information talent base. Agricultural Universities and colleges in Jilin Province as the empirical, analysis and comparison of the advantages of information technology disciplines strength, with a clear location of characteristic agriculture, information technology subjects in school, put forward countermeasures for, in order to enhance the competitiveness of advantageous disciplines, prompting the discipline advantage to better serving the social and economic development.

\section{Research objectives, main contents, key points and innovations of this paper}

Agricultural Universities and colleges in Jilin Province as the breakthrough point, combing of Jilin Province agricultural information technology development strategy and the key disciplines in universities and colleges in the province group construction history and reference to foreign first-class university in the world of similar discipline construction based on the experience, using the web of science subject evaluation tool and the advice amount method, combined with ESI (Essential Science Indicators Database, comparative analysis and evaluation of Jilin Province Agricultural Colleges and universities the advantages of information technology disciplines strength, clear Jilin Province Agricultural Colleges and universities the advantages of information technology subject position proposed countermeasures to enhance the competitiveness of the agricultural colleges and universities information technology advantage discipline.

(1) In order to guide the subject group, the subject of computer software and hardware is constructed.

Effect characteristics of discipline cluster based on, our school should be to level the advantage of software engineering discipline for building discipline cluster based, of the school of computer science and technology, information and computing science, electronic science and technology, information management system, networking, automation six professional coordinated development, in order to produce a comprehensive discipline group, and build the new professions and disciplines.

(2) Taking computer major as the core, and strive to create first-class advantages of agricultural information technology disciplines, highlighting the characteristics of Agriculture

The biggest weakness of present school disciplines is subject to scattered resources, interval too much, lack of core competitiveness, lack of significant achievements, highlighting the agricultural characteristics is not enough, high-end limited impact. Therefore, the construction of information technology subject in addition to the conventional introduction of a high level of teachers, set up a high level team, to improve the quality of personnel training, improve the scientific research and social service level substandard, with emphasis on integration of research resources, the integration of the scientific research strength, the characteristics of the highlight and strengthen.

(3) The construction and management platform of the discipline group is built with the major issues and major projects as the carrier. 
Discipline construction group of academic team focuses on creating interdisciplinary knowledge transfer atmosphere, encourage team to carry out joint declaration of the subject, good project management environment, will promote the subject construction and its development to build a good platform.

(4) To evaluate the advantages of agricultural colleges and universities to explore the strength of the foundation, to explore and enhance the information technology in Jilin Province, the strength of the field of information technology to measure the strength of the discipline

To Jilin province colleges and universities information technology disciplines is empirical, on the strength of analysis and evaluation, mainly from the academic team strength, strength of scientific research, personnel training strength, academic reputation strength evaluation of five hands, to build the advantage of information technology subject strength evaluation index system, Jilin province colleges and universities information technology subject development trend judgment, find out the advantage of agricultural information technology course in Colleges and universities, to provide theoretical support for the sustainable development of Jilin Province Agricultural College of information technology professional. Puts forward the countermeasures and measures to strengthen the information technology advantage in Jilin Province, the strength of the subject, and improve the competitive power of the subjects of higher education.

\section{Conclusion}

First, agricultural colleges and universities were the advantages of information technology and the discipline group construction, can break existing professional, the faculties of the barrier, forming by the leading discipline, discipline system, discipline and related disciplines support, is conducive to the promotion of interdisciplinary and cross disciplinary, fusion and penetration, form interdisciplinary interconnected complementary, symbiotic mechanism, to achieve comprehensive effect in the development of the discipline, cross effect and horizontal effect, the characteristics and advantages of the integration of multidisciplinary, cultivate new discipline growth, optimizing the structure of disciplines;

Second, to optimize the academic team, innovative team building, joint research, bear and agricultural development is closely related to the major comprehensive subject, enhancement to carry out frontier research and technology innovation ability, create great achievements in scientific research, enhance the level of scientific research, strengthen agricultural colleges and universities of agricultural information service function;

Third, is conducive to the realization of the infiltration of information of hard and soft technologies, fully absorb the theory of the subject, knowledge, methods, in the wider field training students' humanistic spirit and scientific spirit, and create conditions for the growth of complex, innovative talents;

Fourth, it is advantageous to realize the optimization of resource allocation, resource sharing, and the maximum efficiency of the use of higher education resources, improve the efficiency of running a school, and promote the development of subjects and schools.

\section{Acknowledgements}

This work was supported by Education Science Planning Project in Jilin Province” Research on the construction of information technology superiority subject group with agricultural characteristics

(GH150215) ”, and Jilin Agricultural University teaching reform project in 2015” Construction of multidimensional practice platform for college students' innovation ability training(2015xjzd26)”

\section{References}

[1] Zhang Xiaoning. The implementation of the superior discipline construction project construction of the domestic first-class, international advanced high level disciplines -- take Jiangsu Province as an example [J]. degree and graduate education, 2012,09:54-57. 
[2] Lou Yuzhen, Zhao Peng, Xu Shiyuan. The principle and approach of the construction of the dominant subject and characteristic discipline of University [J]. China geology education, 2006,02:37-40.

[3] Xu Cuihua. The current situation, problems and Countermeasures of the superior subjects in universities and Colleges -- Taking Jiangsu Province as an example [J]. Heilongjiang higher education research, 2013,04:65-68.

[4] Ma Mingzhong. Reflections on the construction of the advantages of local colleges and universities [J]. educational exploration, 2015,01:60-64.

[5] Yang Yanni, Shenyang. The discovery of the national dominant discipline field based on activity and influence -- a case study of communication science, [J]., 2015,08:54-59+76.

[6] Wang Chunhui. Promote the construction of the University's dominant disciplines to promote the level of running a school to enhance the [J]. China's higher education, 2015,12:50-52.

[7] Yu Xiao, Zheng Suli, Wu Wei. Research on the characteristics of the patent development of local colleges and universities and its correspondence with the superior discipline -- Based on the perspective of industry university research collaboration $[\mathrm{J}]$. higher engineering education research, 2016,01:76-81.

[8] Yin Xiangwen. Innovative ideas to promote the advantages of [J]. follow the rules of discipline construction of higher education in Jiangsu, 2011,03:1-4.

[9] Wang Guifen, Cheng East China. A discussion on the cultivation of superior subjects and specialties in Universities -- Based on the perspective of interactive relationship [J]. higher education of agriculture, 2011,09:70-72.

[10] Liu Guoyu. Advantage disciplines in Universities: connotation, significance and construction of [J]. graduate education research, 2015,06:67-70. 